\title{
The Rutherglen bug: an agricultural pest and an under-recognised biting culprit
}

Nikki R Adler ${ }^{1,2}$, Harini Rajogopal Bala ${ }^{3}$, Rosemary L Nixon ${ }^{3}$

${ }^{1}$ Alfred Hospital, Melbourne, Victoria, Australia

${ }^{2}$ School of Public Health and Preventive Medicine, Melbourne, Victoria, Australia

${ }^{3}$ Occupational Dermatology Research and Education Centre, Skin and Cancer Foundation Inc,

Carlton, Victoria, Australia

Corresponding author:

Dr Nikki R Adler

Alfred Hospital, Melbourne, Victoria, Australia

Phone: (03) 90762000

Email: N.Adler@alfred.org.au

Word count: 483

Figures: 1

Tables: 0

Conflicts of interest: none

Funding sources: none

Author contributions: NRA drafted and revised the manuscript; HRB revised the manuscript; RLN critically revised the manuscript for important intellectual content.

Acknowledgements: We acknowledge Mr Simon Hinkley, Entomologist from the Melbourne Museum Discovery Centre, Melbourne, Australia, for providing identification of the Rutherglen bug, Nysius vinitor.

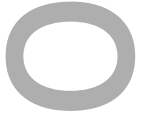

Key words: rural dermatology, insect bites, arthropod bites, Rutherglen bug

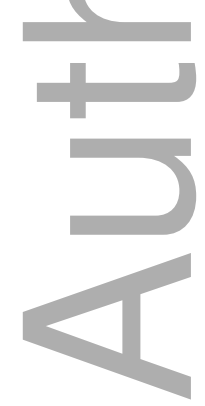

This is the author manuscript accepted for publication and has undergone full peer review but has not been through the copyediting, typesetting, pagination and proofreading process, which may lead to differences between this version and the Version of Record. Please cite this article as doi: $10.1111 /$ ajd.12666

This article is protected by copyright. All rights reserved 
DR. NIKKI RAE ADLER (Orcid ID : 0000-0002-7972-9050)

\section{Received Date : 15-Mar-2017}

Accepted Date : 16-Mar-2017

Article type : Case Letter

An 81-year-old woman presented to a dermatologist during spring of 2016 with a 1-2 week history of multiple pruritic, mildly-tender, non-follicular papules with central puncta, which were asymmetrically distributed over her chest and upper extremities. There was no acral or mucous membrane involvement. The clinical presentation was consistent with insect bites. The patient was systemically well with no evidence of an allergic reaction. The patient's medical history was significant for hypertension and gastroesophageal reflux disease. There were no recent changes to her long-term medication (irbesartan, amlodipine and esomeprazole) and she had no known drug allergies.

The patient reported finding hundreds of small, greyish-brown, winged bugs in her home at the time of the insect bites. The patient had no known psychiatric history and she denied illicit drug use. She collected a sample of the bugs from her house, which was close to the Murray River in New South Wales, Australia, and $17 \mathrm{~km}$ from Rutherglen. These specimens were identified by an expert entomologist at the Melbourne Museum Discovery Centre as the Rutherglen bug, Nysius vinitor.

The Rutherglen bug is a native agricultural pest that can damage crops and pastures throughout Australia and is found in New South Wales, Victoria, South Australia, southern Western Australia and Queensland. ${ }^{1,2}$ Breeding of this heteropteran bug commences in early spring; large numbers are often present in November and December when these bugs migrate into cropping areas depending on seasonal wind patterns. ${ }^{1,2}$ Adult bugs are 3-4 mm long, narrow-bodied, greyish-brown in colour, with prominent black eyes and folded wings (Figure 1). ${ }^{3}$

Rutherglen bugs are considered to be generalist herbivores. Indeed, almost all hemiptera (the order of Nysius vinitor) feed on plants, with the exception of the Cimicidae family, which includes bed bugs (Cimex lectularius and Cimex hemipterus), and the Ruduviidae family, which includes kissing bugs (Triatoma species), that are known to feed on humans. ${ }^{4}$ In the late 1980s, Southcott reported that the Rutherglen bug may become a nuisance in homes and cause painful bites to humans. ${ }^{5}$ Aside from that report, Rutherglen bugs were thought to have little interest in humans. To the authors' knowledge, this case represents the first report in the scientific literature of insect bites from Rutherglen bugs for over 
two decades. While the authors acknowledge the possibility that the patient's bites may have been caused by a different insect, the specific arthropod exposure as a consequence of the household infestation and the temporal relationship would appear to make the Rutherglen bug the most likely culprit. We therefore report a common presentation with an unusual aetiology.

While arthropod bites often pose as a minor nuisance only, secondary bacterial infection, transmission of insect-borne illnesses and severe allergic reactions are all potential complications. Knowledge of local arthropod fauna by dermatologists is pivotal in making the diagnosis of arthropod bites. Therefore, awareness of novel biting insects, such as the Rutherglen bug, is of public health interest to practicing Australian dermatologists.

\section{References}

1. Micic, S. Diagnosing Rutherglen bug. Department of Agriculture and Food, Government of Western Australia. Western Australia, Australia. [updated 2015 April 15; accessed 2016 Dec 13]. Available from https://www.agric.wa.gov.au/mycrop/diagnosing-rutherglen-bug.

2. Hangartner S, McDonald G. Rutherglen bug: Nysius vinitor. Cesar, Sustainable Agriculture. Parkville, Victoria, Australia. [updated 2015 Feb; accessed 2016 Dec 13]. Available from http://www.cesaraustralia.com/sustainable-agriculture/pestnotes/insect/Rutherglen-bug.

3. Malipatil, M. Rutherglen bug. The Pest and Disease Image Library (PaDIL), Plant Biosecurity Cooperative Research Centre, Canberra, Australia. [updated 2007 July; accessed 2016 Dec 13]. Available from http://www.padil.gov.au/pests-and-diseases/pest/main/136115.

4. Steen CJ, Carbonaro PA, Schwartz RA. Arthopods in dermatology. J Am Acad Dermatol. 2004; 50: 819-842.

5. Southcott RV. Some harmful Australian insects. Med J Aust 1988: 149:656-662.

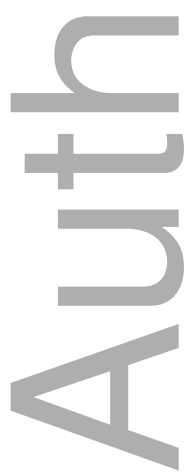


Figure 1. Adult Rutherglen bug, Nysius vinitor, a 3-4 mm long, narrow-bodied, grey-brown insect with folded wings and dark eyes. Image from Maipatil. ${ }^{3}$
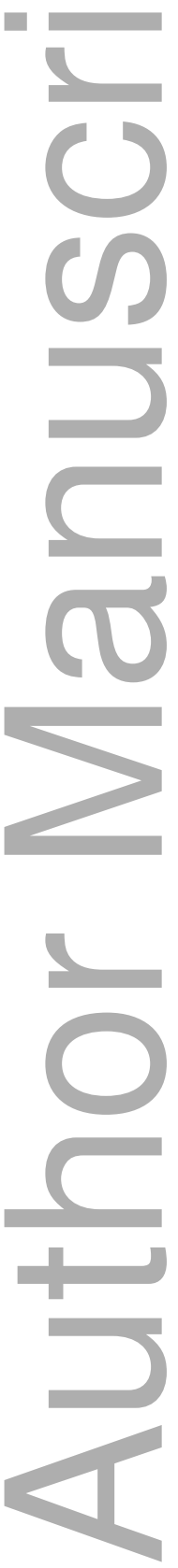

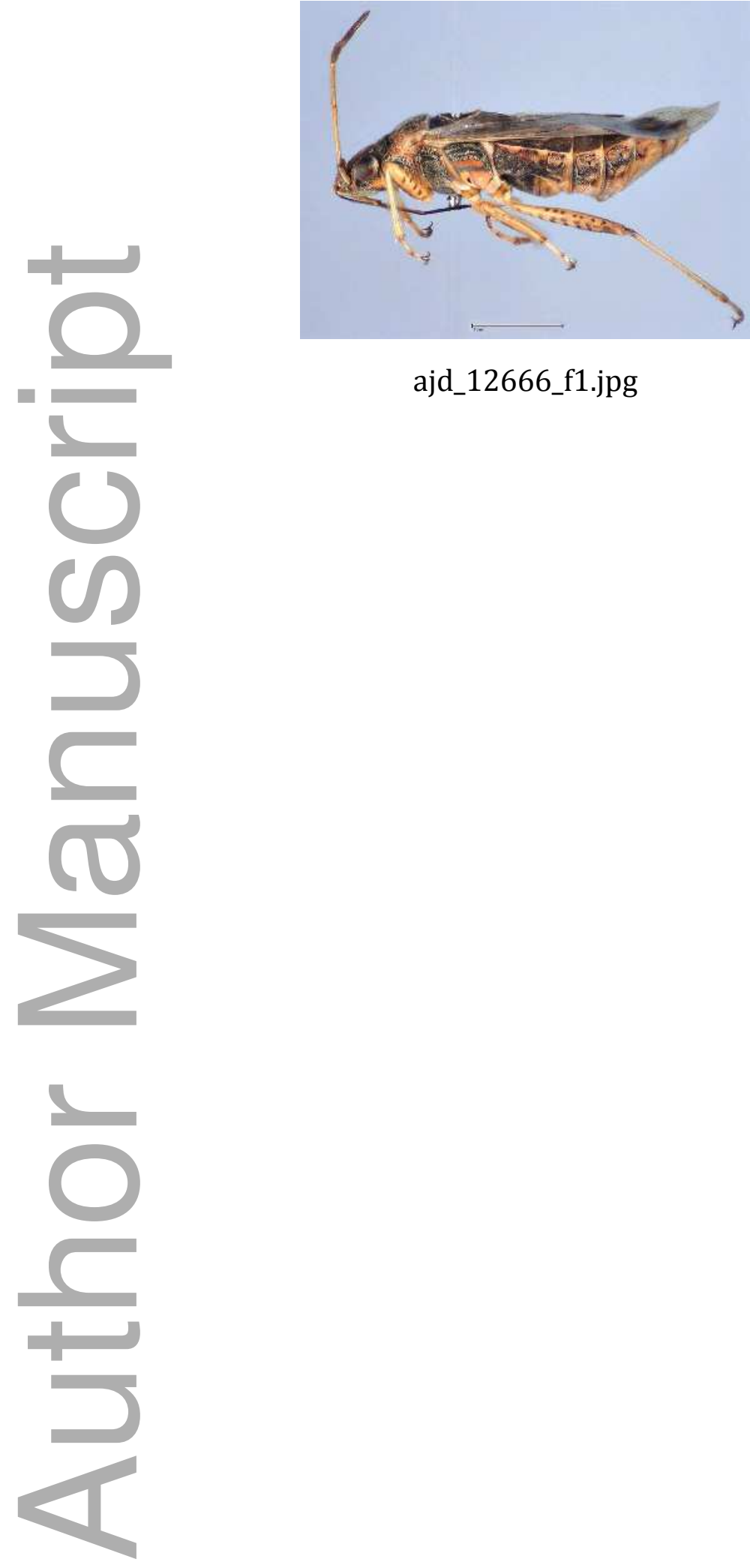

ajd_12666_f1.jpg

This article is protected by copyright. All rights reserved 


\section{University Library}

\section{- M M N E R VA A gateway to Melbourne's research publications}

Minerva Access is the Institutional Repository of The University of Melbourne

Author/s:

Adler, NR;Bala, HR;Nixon, RL

Title:

Rutherglen bug: An agricultural pest and an under-recognised biting culprit

Date:

2017-08-01

Citation:

Adler, N. R., Bala, H. R. \& Nixon, R. L. (2017). Rutherglen bug: An agricultural pest and an under-recognised biting culprit. AUSTRALASIAN JOURNAL OF DERMATOLOGY, 58 (3), pp.245-246. https://doi.org/10.1111/ajd.12666.

Persistent Link:

http://hdl.handle.net/11343/293007 